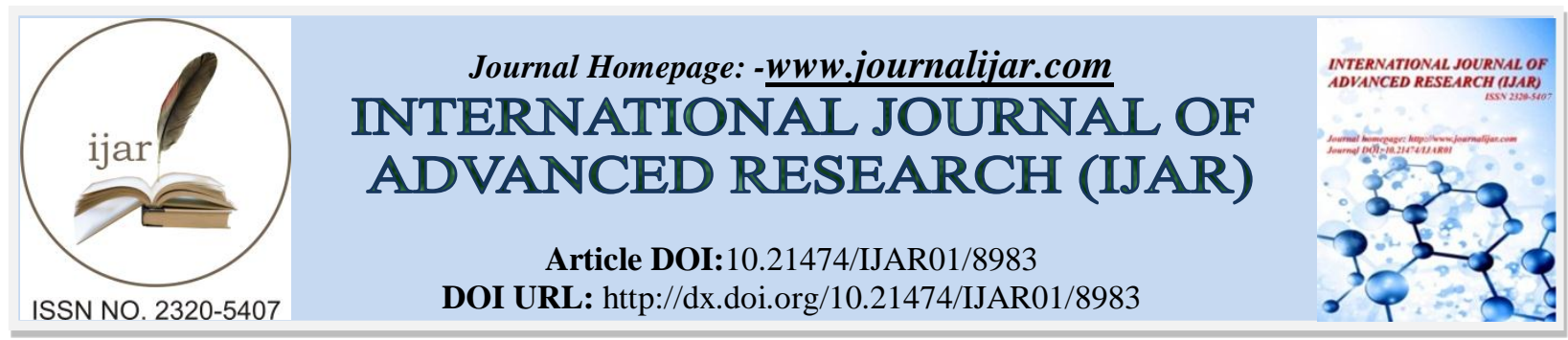

CASE REPORT

\title{
MIDLINE DIASTEMA CLOSURE USING DIRECT LIGHT CURED COMPOSITE RESIN - A CASE SERIES.
}

Indrajit Biswas ${ }^{1}$, Sampurna Dutta Gupta ${ }^{1}$, Deepshikha Chowdhury ${ }^{1}$ and Paromita Mazumdar ${ }^{2}$.

1. Post graduate trainee, Department of Conservative dentistry and Endodontics, Guru Nanak Institute of Dental Sciences and Research, Kolkata.

2. Professor and Head of the Department, Conservative dentistry and Endodontics, Guru Nanak Institute of Dental Sciences and Research , Kolkata.

\section{Manuscript Info}



Manuscript History

Received: 25 February 2019

Final Accepted: 27 March 2019

Published: April 2019

Key words:-

direct composite resin, esthetic, midline diastema.
Abstract

Maxillary anterior spacing or diastema is a common aesthetic complaint of patients. Midline diastema has multifactorial etiology such as labial frenulum, microdontia, mesiodens, peg-shaped lateral incisors, agenesis, cysts, habits such as finger sucking, tongue thrusting, or lip sucking, dental malformations, genetics, proclinations, dental-skeletal discrepancies, and imperfect coalescence of interdental septum. Appropriate technique and material for effective treatment are based on time, physical, psychological, and economical limitations. Direct composite resins in diastema cases allow dentist and patient complete control of these limitations and formation of natural smile. The case series describes three cases of anterior midline diastema closure using direct composite resin. Patients were recalled for follow up upto 6 months where no discolouration, sensitivity or fracture was observed. Thus direct composite resin restorations for midline diastema closure can be considered to be highly esthetic and durable and could satisfy the esthetic demands of the patients presented in the cases.

Copy Right, IJAR, 2019,. All rights reserved.

\section{Introduction:-}

Midline diastema - spacing present between maxillary central incisors is the most common form of malocclusion, which is considered to be multifactorial in nature. The incidence of diastemas vary greatly with age and race. The space can be a normal growth characteristic during the primary and mixed dentition and generally is closed by the time the maxillary canines erupt. In adults, the most common factors in the development of diastemas are tooth-size discrepancies and excessive vertical overlap of the incisors. Other less frequent, but important, contributing factors are Incisor mesiodistal angulations, generalized spacing, labiolingual incisor inclination, high labial frenal attachment and pathological conditions. This spacing leads to disharmony of smile, impairment of phonetics and impairment of oral hygiene. ${ }^{[1]}$

A carefully developed differential diagnoses allows the practitioner to choose the most effective treatment plan. Diastemas based on tooth-size discrepancy are most amenable to restorative solutions. Midline diastema can be managed by either surgical, orthodontic, periodontal, restorative and prosthodontic procedures or a combination of the above mentioned procedures. The increased patient demand for minimally invasive aesthetic procedures and the 
improved physical properties of current composite materials has resulted in the extensive utilization of direct bonding of composite resin to anterior teeth. Contemporary composite materials can be handled throughout the restorative process to achieve the desired morphology and color of the final restoration. Direct resin build up can be a worthy choice to treat diastemas based on tooth-size discrepancy. Recent advancements in direct composite resin gives the dental practitioners an added advantage to perform minimally invasive esthetic dentistry which is conservative as well as less time consuming. Direct composite resin restoration in diastema closure allows both dentist and patient control in the formation of a natural smile. ${ }^{[2]}$ Composite resins can duplicate the details of pellucid and opalescence. ${ }^{[3,4]}$ They can impart a natural colour to the restoration which is undetectable to human vision, when correct techniques are employed. Also an added advantage of these materials is that they are economical.

This case series describes three case reports of esthetic management of midline diastema using direct composite resin after informed consent was obtained from all three patients.

\section{CASE : 1}

A 40 year old female patient reported to the department of Conservative Dentistry and Endodontics with the chief complaint of gap between her upper front teeth. Angle's Class I malocclusion with normal over jet and over bite was recorded. The patient was made aware of the different treatment modalities, but she chose to go for the restorative procedure.

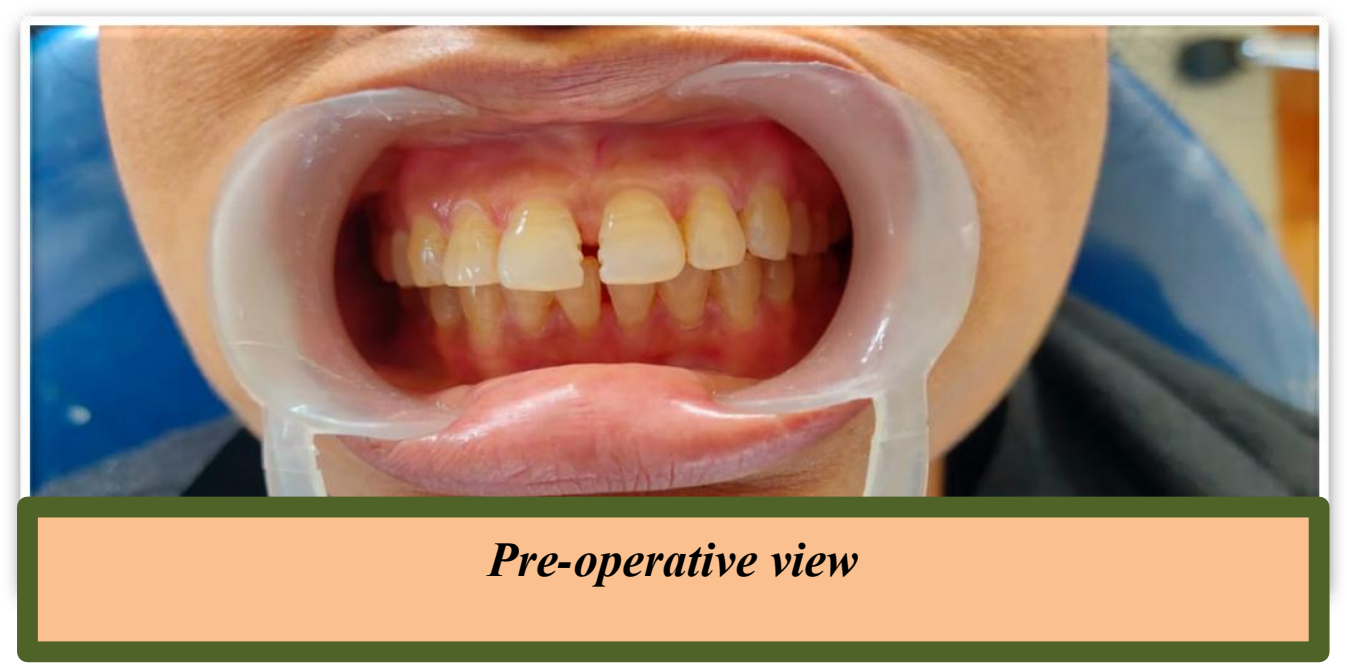

\section{Clinical Technique:}

A gap of $2 \mathrm{~mm}$ was recorded between the maxillary central incisors on clinical examination. Shade selection was done using vita classical shade guide under natural daylight. The central incisors were retracted by using retraction cord. 37\% phosphoric acid (Etching Gel, Kerr, USA) was applied on the mesial surface to be restored for 15 seconds and then rinsed and dried using blotting paper (Wattman). Mylar strip was placed and bonding agent (Opti Bond S, Kerr ,USA) was applied and polymerized for 20 seconds with a LED light generator (Demi Led Light Curing System, Kerr, USA). 

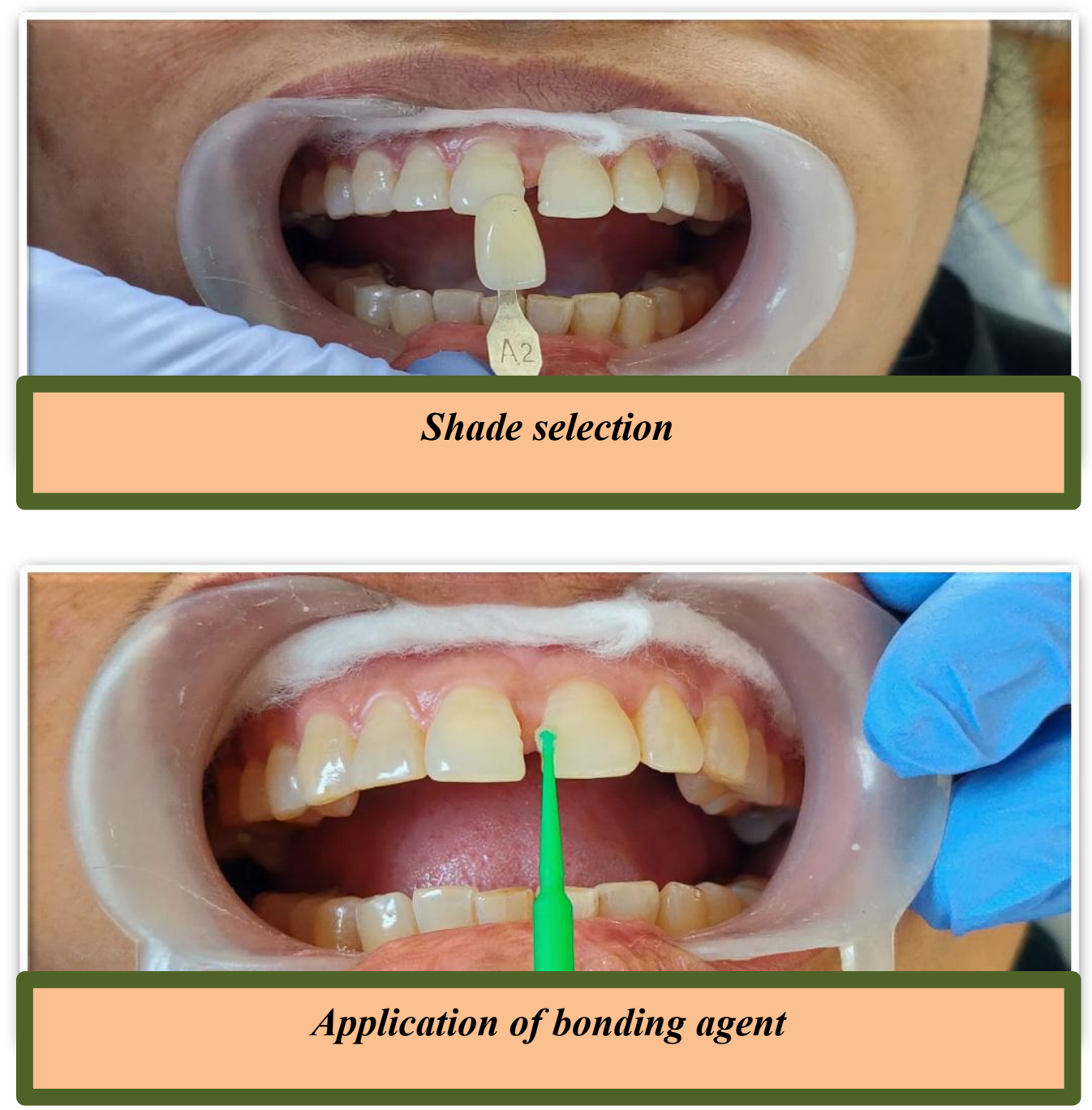

A thin layer of composite resin was used palatally as enamel. ( Herculite Precis A 2 enamel) Herculite Precis A2 dentin shade composite resin was used as dentin layer and a thin layer of A2 enamel shade was used as the top enamel layer. Polishing discs (Ultra Gloss Composite Polishing System, Axis, USA) were used for detailed polishing from rough to fine grains. Oral hygiene instructions was given to the patient and finger massaging of the interdental gingival was advised. 

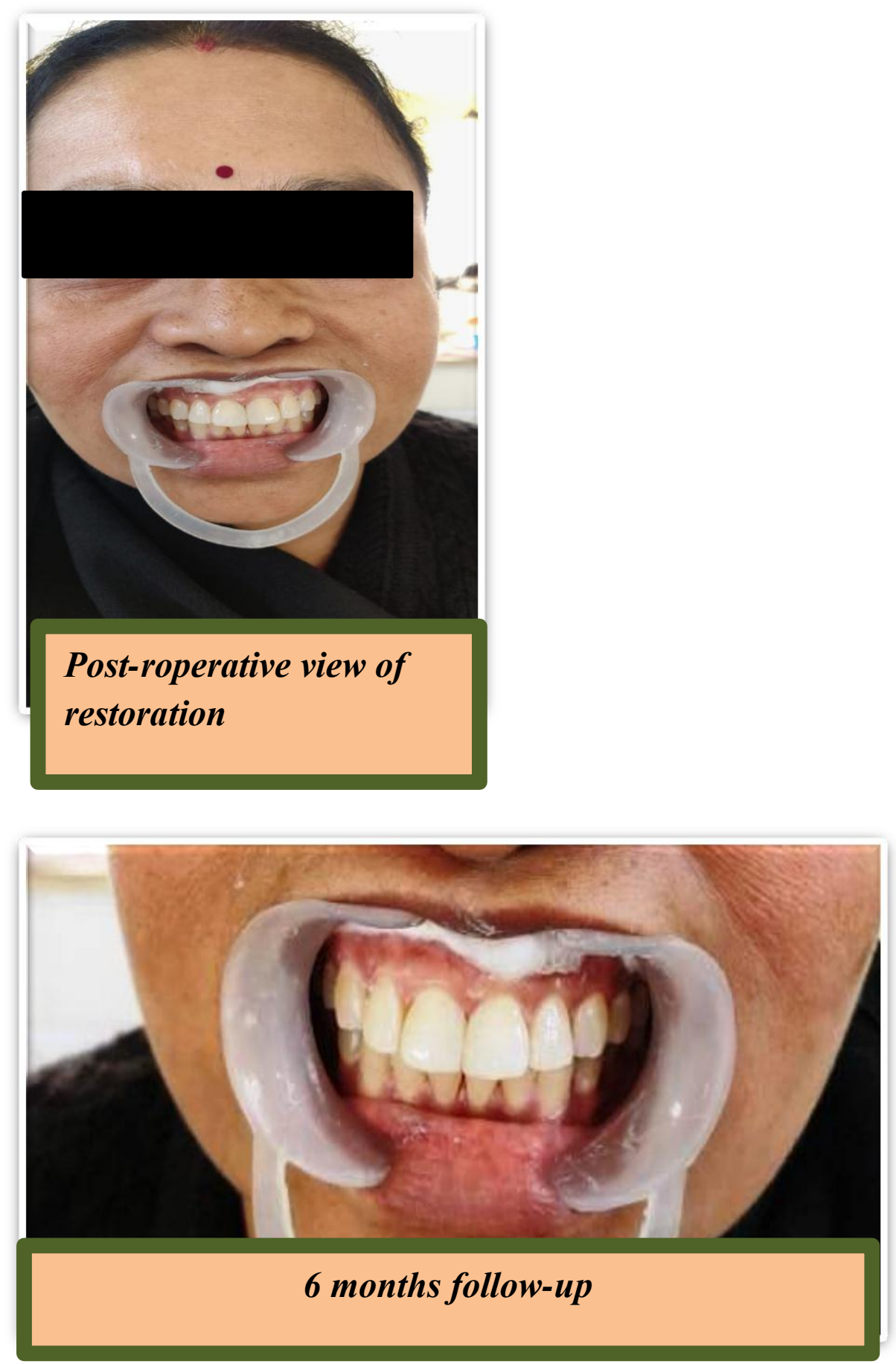

The patient was recalled after 6 months, no significant differences were observed on comparing the retention, marginal adaptation, anatomical form, discolouration and surface texture. The patient was satisfied with the restoration.

CASE: 2

A 30-year-old female came to the department of Conservative Dentistry and Endodontics, complaining about the space in the upper middle of front teeth region. The patient didn't want orthodontic or prosthodontic treatment options. So, the treatment plan to attain an esthetically favourable relation between the maxillary anterior teeth involved closing the diastema using composite resin restorations.

Clinical Technique: 
A clinical examination revealed $2 \mathrm{~mm}$ space between maxillary central incisors, with favourable gingival hygiene. The patient had Angle's Class I malocclusion with normal overjet and over bite. Shade selection was done using vita classical shade guide under natural daylight. The central incisors were retracted by using retraction cord. Etching was done using 37\% phosphoric acid (Etching Gel, Kerr, USA), it was applied on the mesial surface to be restored for 15 seconds and then rinsed off.
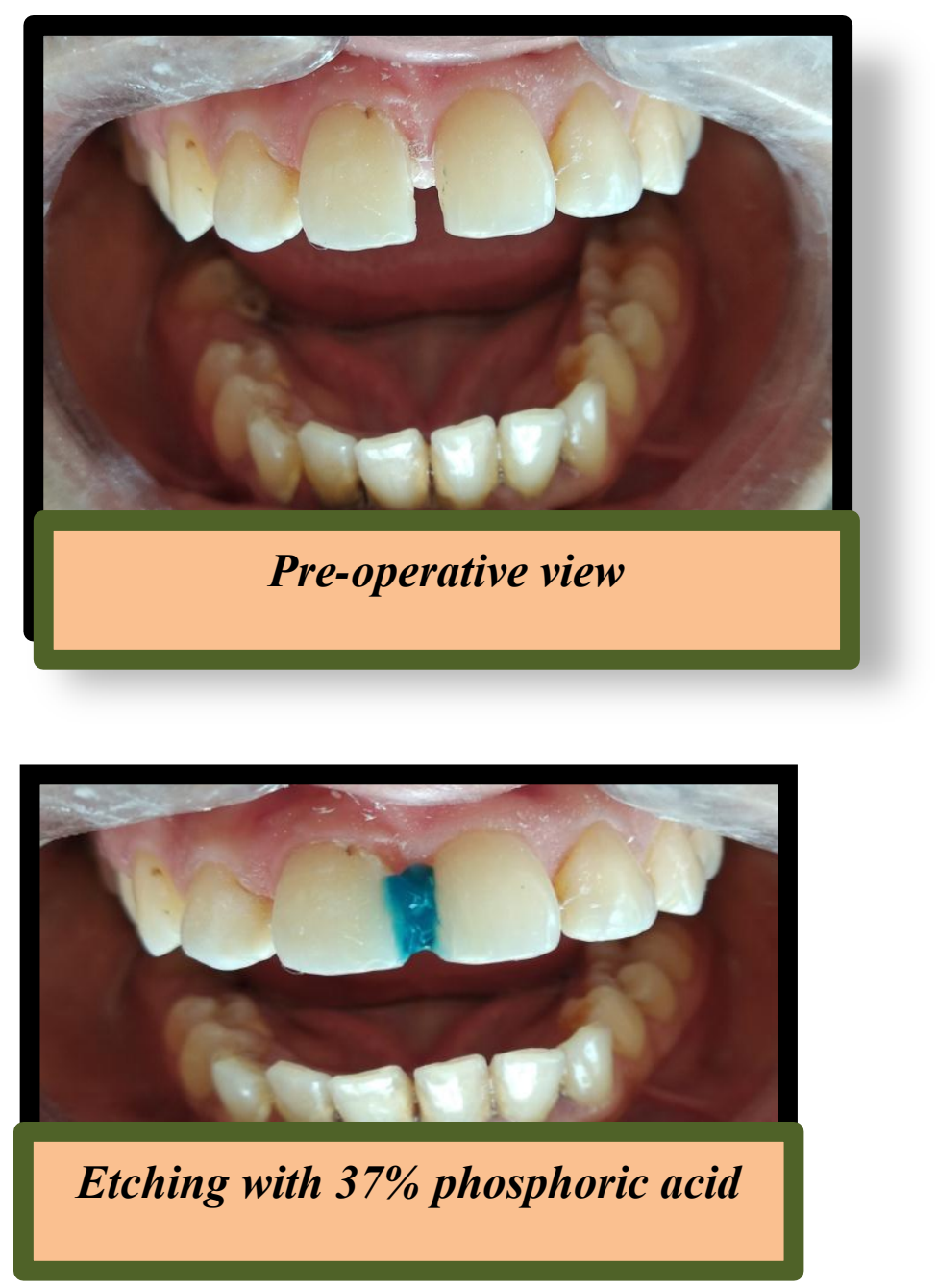

Te Econom Bond (Ivoclar Vivadent) adhesive was applied and light cured for 15 seconds. The proximal walls of the central incisors were formed with clear matrix strips. Once the boundaries of the restoration had been identified, shade A2 dentin Tetric N ceram composite resin ( Ivoclar Vivadent) composite resin was used to build the bulk of the dentine. This was overlaid with a $0.5 \mathrm{~mm}$ layer of translucent A2 enamel shade of Tetric $\mathrm{N}$ ceram composite resin ( Ivoclar Vivadent). Finishing and polishing was done using composite polishing kit by Shofu. Oral hygiene instructions was given to the patient and finger massaging of the interdental gingival was advised. 

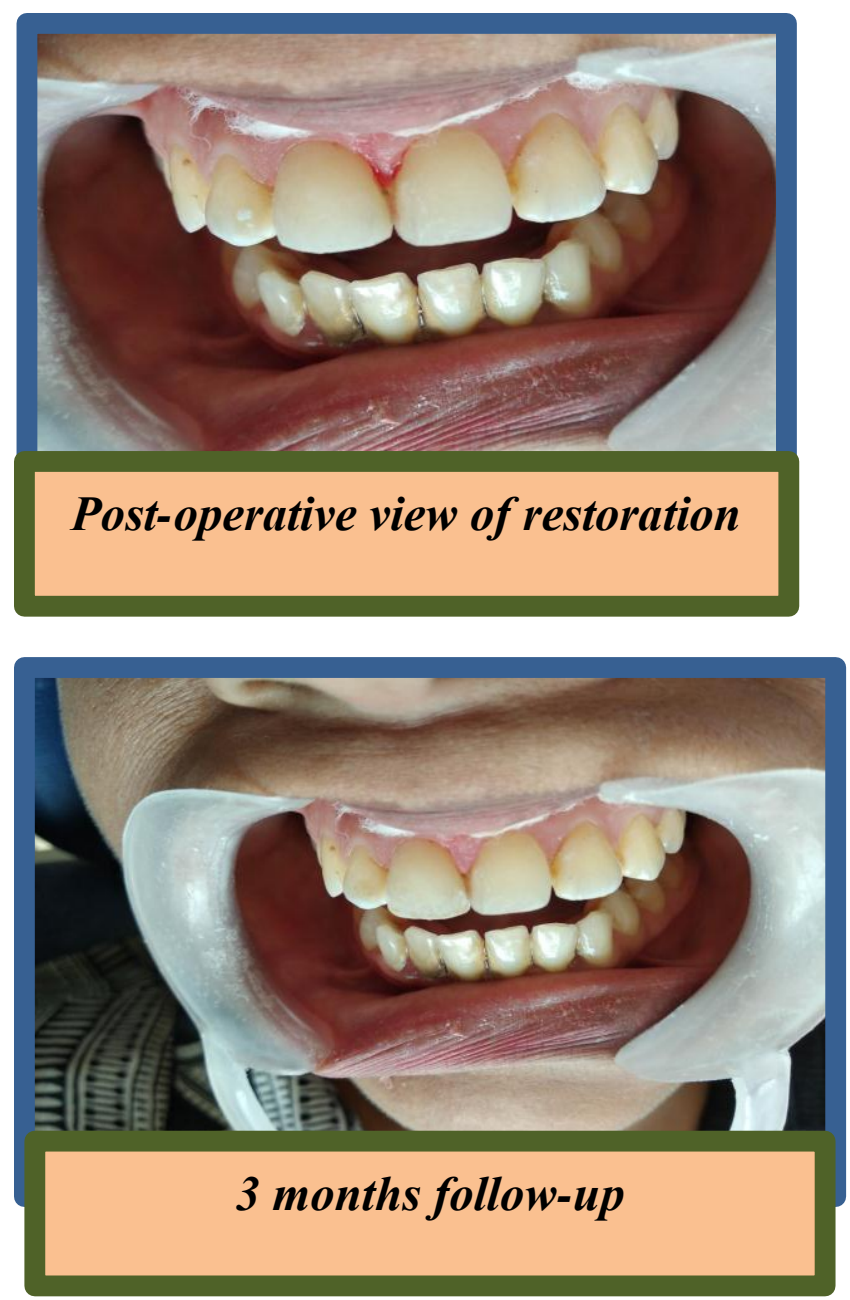

A 3 month follow up of the restoration was done as the patient did not report to the department after that. No significant differences were observed on comparing the retention, marginal adaptation, anatomical form, discolouration and surface texture.

\section{CASE : 3}

A 37 year old male patient reported to the department with the chief complaint of gap between his upper front teeth. Angle's Class I malocclusion with normal over jet and over bite was recorded. The patient chose to go for the restorative procedure when given the option of different treatment modalities were presented to him. 


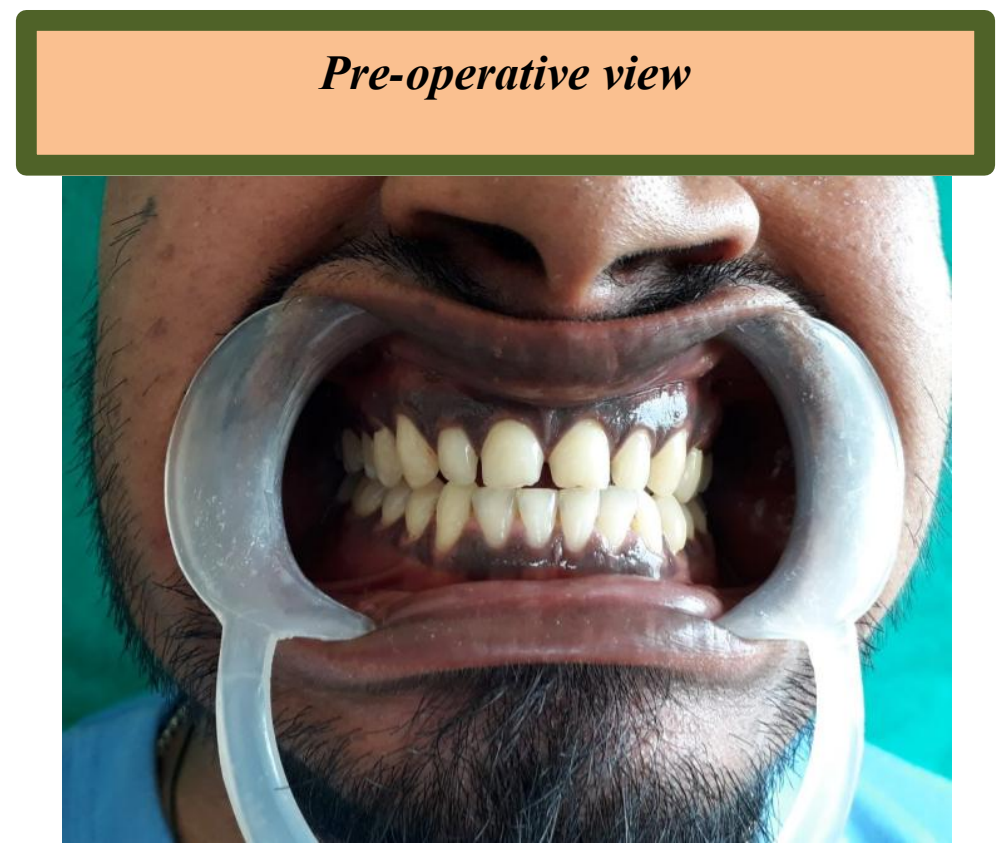

\section{Clinical Techniques:}

On clinical examination, a gap of $1.5 \mathrm{~mm}$ was recorded between the maxillary central incisors. Shade selection was done using vita classical shade guide under natural daylight. The central incisors were retracted by using retraction cord. Etching was done using 37\% phosphoric acid (Etching Gel, Kerr, USA), it was applied on the mesial surface to be restored for 15 seconds and then rinsed off. Mylar strip was placed and bonding agent (Opti Bond S, Kerr ,USA) was applied and polymerized for 20 seconds with a LED light generator (Demi Led Light Curing System, Kerr, USA). A thin layer of composite resin was used palatally as enamel. ( Herculite Precis A 1 enamel) Herculite Precis A1 dentin shade composite resin was used as dentin layer and a thin layer of A1 enamel shade was used as the top enamel layer. Finishing and polishing procedure was performed with Soflex Discs (Sof-Lex ${ }^{\mathrm{TM}}$ XT Discs, 3M ESPE, USA) (from coarse to fine). Oral hyegiene instructions was given to the patient and finger massaging of the interdental gingival was advised.

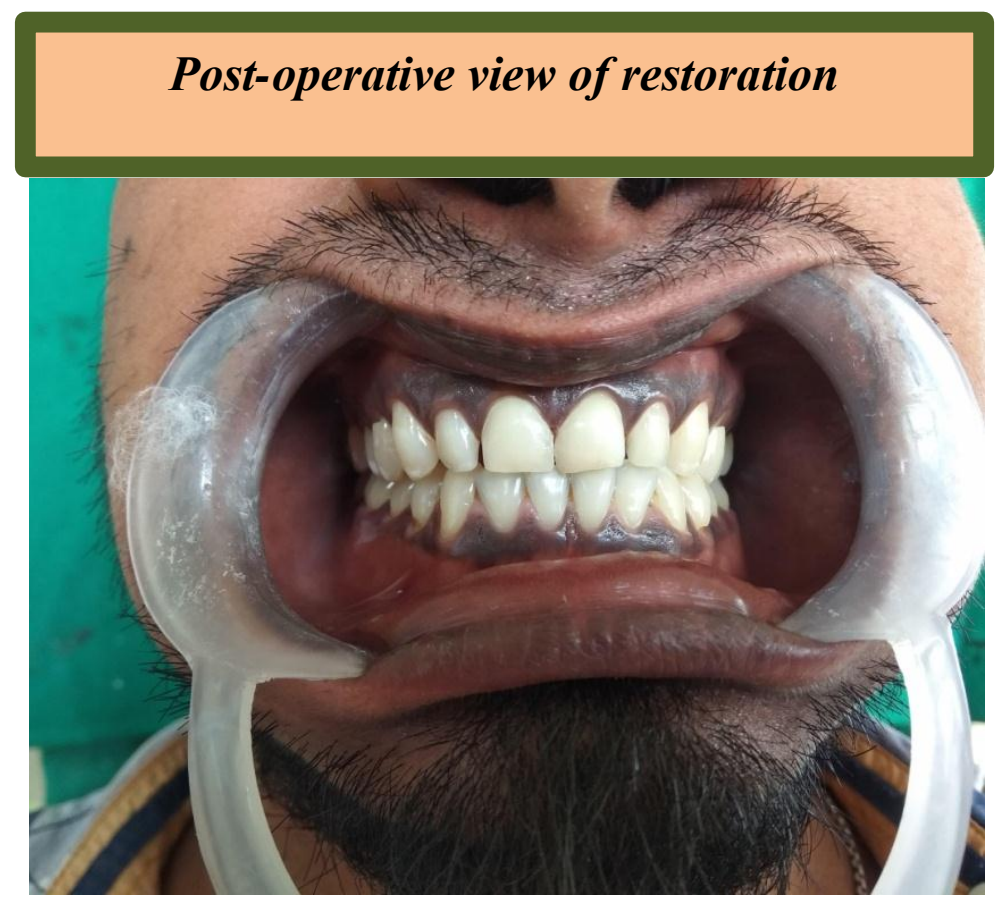


6 months follow up showed that the patient was asymptomatic with no post operative sensitivity, discolouration of the restoration, or fracture of the restoration.

\section{Discussion:-}

In aesthetic dentistry, these restorations offer numerous advantages that other possible treatment options such as ceramic veneers and orthodontic treatment do not have. The direct composite resin restorations can be placed in a single visit, often do not require preliminary models or wax-ups, and do not involve laboratory fees that escalate costs. They are kinder to the opposing dentition compared to ceramic materials . ${ }^{[3]}$

The three cases were restored using direct composite by the layering technique. It is a minimally invasive approach with reproduction of excellent contour. ${ }^{[4,5]}$ It is also economic and satisfactory result can be achieved in single sitting

The composite materials used have proper handling and esthetic properties with high filler content and small particle size. The technique is easy to perform with creation of proper midline and optimum contact area. ${ }^{[6]}$

Rubber dam isolation was not done in the cases because it is difficult to visualise midline of face after application of rubber dam. ${ }^{[7]}$

Patients were highly satisfied with the end results and were instructed to avoid pigmented liquids and was advised to floss regularly. The patients were asked for regular follow ups till 6 months. At 6 months recall the general outlook of the maxillary anterior teeth was considered natural and aesthetic. Clinically, the restorations had no fractures and also the restoration margins on both maxillary central incisors demonstrated no discolorations in all three cases. Although 6 months follow-up does not seem long enough and further long term follow-ups are required, restoration problems such as marginal leakage, discolorations, fractures, and debonding for composite resins generally merge within 6 months after the treatment.

\section{Conclusion:-}

The minimal invasive cosmetic approach adopted in these cases satisfied the esthetic requirements of the patients. The natural tooth structure was tried to be replicated with maximal possible preservation.

\section{References:-}

1. K. Koora, M. S. Muthu, and P. V. Rathna, "Spontaneous closure of midline diastema following frenectomy," Journal of Indian Society of Pedodontics and Preventive Dentistry, vol. 25, no. 1, pp. 23-26, 2007.

2. H. J. Keene, "Distribution of diastemas in the dentition of man," American Journal of Physical Anthropology, vol. 21, no. 4, pp. 437-441, 1963.

3. J. T. Kaimenyi, "Occurrence of midline diastema and frenum attachments amongst school children in Nairobi, Kenya," Indian Journal of Dental Research, vol. 9, no. 2, pp. 67-71, 1998.

4. Weber, Quoted in: Orthodontic Principles and Practice, edited by: T. M. Graber, W.B. Saunders Company, 3rd edition, 1972.

5. O. M. Tanaka, A. Y. K. Morino, O. F. Machuca, and N. Á. Schneider, "When the midline diastema is not characteristic of the 'ugly duckling' stage," Case Reports in Dentistry, vol. 2015, Article ID 924743, 5 pages, 2015.

6. N. Blitz, "Direct bonding in diastema closure—high drama, immediate resolution," Oral Health, vol. 86, no. 7, pp. 23-29, 1996.

7. P. R. Chalifoux, "Perception esthetics: factors that affect smile design," Journal of Esthetic and Restorative Dentistry, vol. 8, no. 4, pp. 189-192, 1996. 